UCRL-JC-130860

PREPRINT

\title{
The Safety and Environmental Process for the Design and Construction of the National Ignition Facility
}

\author{
S. J. Brereton, J. M. Yatabe, C. A. Taylor
}

This paper was prepared for submittal to the 1998 American Nuclear Society Annual Meeting

Nashville, TN

June 7-11, 1998

May 27, 1998

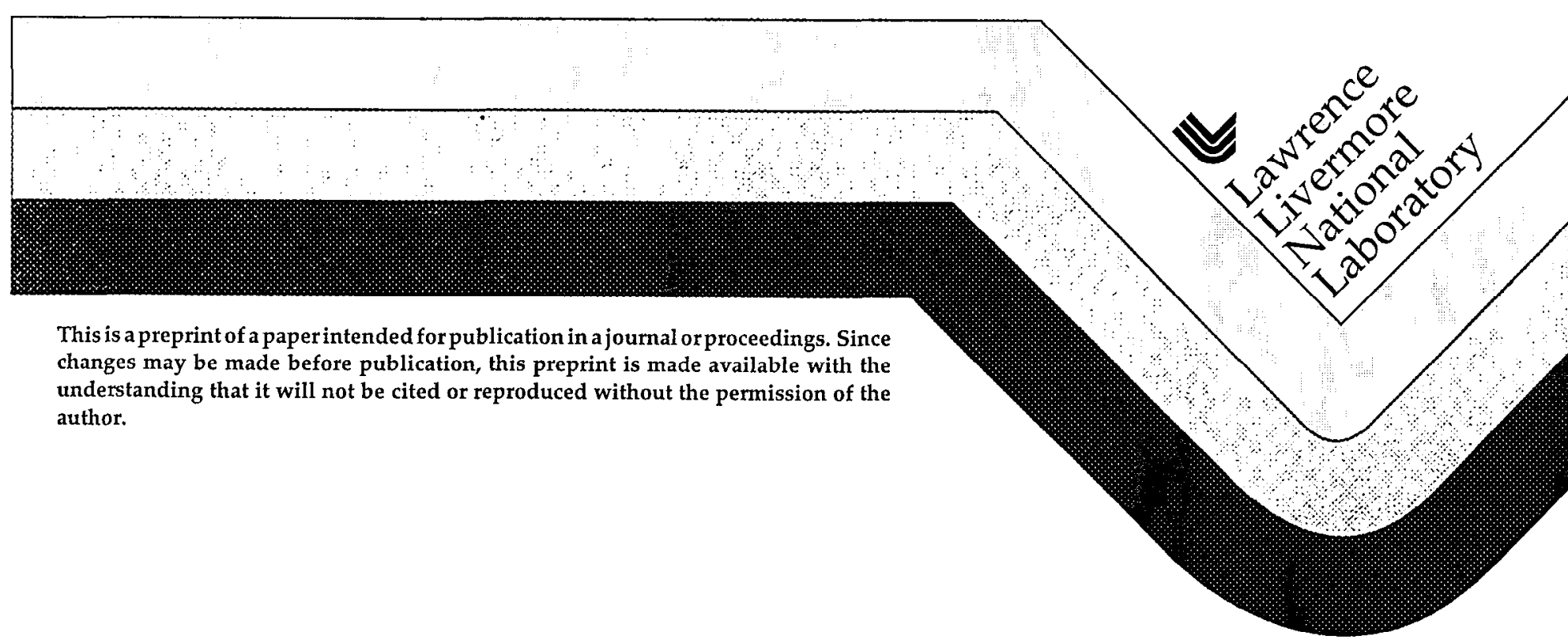




\section{DISCLAIMER}

This document was prepared as an account of work sponsored by an agency of the United States Government. Neither the United States Government nor the University of California nor any of their employees, makes any warranty, express or implied, or assumes any legal liability or responsibility for the accuracy, completeness, or usefulness of any information, apparatus, product, or process

disclosed, or represents that its use would not infringe privately owned rights. Reference herein to any specific commercial product, process, or service by trade name, trademark, manufacturer, or otherwise, does not necessarily constitute or imply its endorsement, recommendation, or favoring by the United States Government or the University of California. The views and opinions of authors expressed herein do not necessarily state or reflect those of the United States Government or the University of California, and shall not be used for advertising or product endorsement purposes. 


\section{THE SAFETY AND ENVIRONMENTAL PROCESS FOR THE DESIGN AND CONSTRUCTION OF THE NATIONAL IGNITION FACILITY"}

Sandra J. Brereton and Jon M. Yatabe

Lawrence Livermore National Laboratory

P.O Box 808, L-493

Livermore, CA 94551

\author{
Charles A. Taylor \\ U.S. Department of Energy, Oakland Operations \\ Lawrence Livermore National Laboratory \\ P.O. Box 808, L-293 \\ Livermore, CA 94551
}

Construction Safety Program and Construction Safety Health and Safety Plans during construction, and Operational Safety Procedures and the Facility Safety Procedure during operation. The NIF ES\&H document trail is shown in Figure 1.

The environmental documentation pathway for NIF involved the preparation of a Programmatic Environmental Impact Statement (which includes a detailed Project Specific Analysis for NIF), issuance of a Record of Decision (ROD), and preparation of a Mitigation Action Plan (MAP), which documents how the environmental impacts of NIF construction and operation will be mitigated. The requirements for an Environmental Impact Statement are given in NEPA and the related DOE Order. ${ }^{2,3}$ In the ROD, the Secretary of Energy formally identified LLNL as the preferred site for NIF. Although the ROD was issued in December of 1996, the environmental pathway has continued to be active. We have invoked several mitigation measures outlined in our MAP, including some specific actions to ensure that we will not disturb several protected/endangered species living on the Livermore site. During the excavation, some buried hazardous material and bones were discovered. We will describe the process followed upon discovering these buried items.

The first of these pathways generates safety basis documentation. This pathway leads from the Preliminary Hazards Analysis (PHA), to the Preliminary Safety Analysis Report (PSAR), to the Final Safety Analysis Report (FSAR). Because NIF was classified as a low hazard, radiological facility, the safety basis documentation process has been governed by DOE Order 5481.1B, Safety Analysis and Review System. ${ }^{1}$ This process has gone very smoothly to date. This paper summarizes some of the specific aspects associated with generating safety basis documentation, and the manner by which we are assuring that the safety basis is maintained current, and that safety commitments made in the safety basis documentation are actually in the design, and ultimately will be in the as-built facility. In addition to safety basis documentation, implementing documents are also generated through this pathway. These include the

\section{SAFETY ANALYSIS PROCESS}

The NIF safety analysis process is depicted in Figure 2. The initial safety analysis document prepared for the NIF was a Preliminary Hazards Analysis (PHA) document. ${ }^{4}$ This was prepared during the NIF Conceptual Design activity and provided an initial identification of the expected hazards at NIF. It also provided initial documentation of the facility hazard classification as low hazard, radiological. This was based on facility inventories, bounding accidents, and the DOE methodology for hazard classification. As a low hazard, radiological facility, NIF presents minor onsite and negligible offsite impacts. A low hazard facility requires a

\footnotetext{
${ }^{\text {a }}$ Work performed under the auspices of the U.S. Department of Energy by Lawrence Livermore National Laboratory under Contract W-7405-Eng-48.
} 


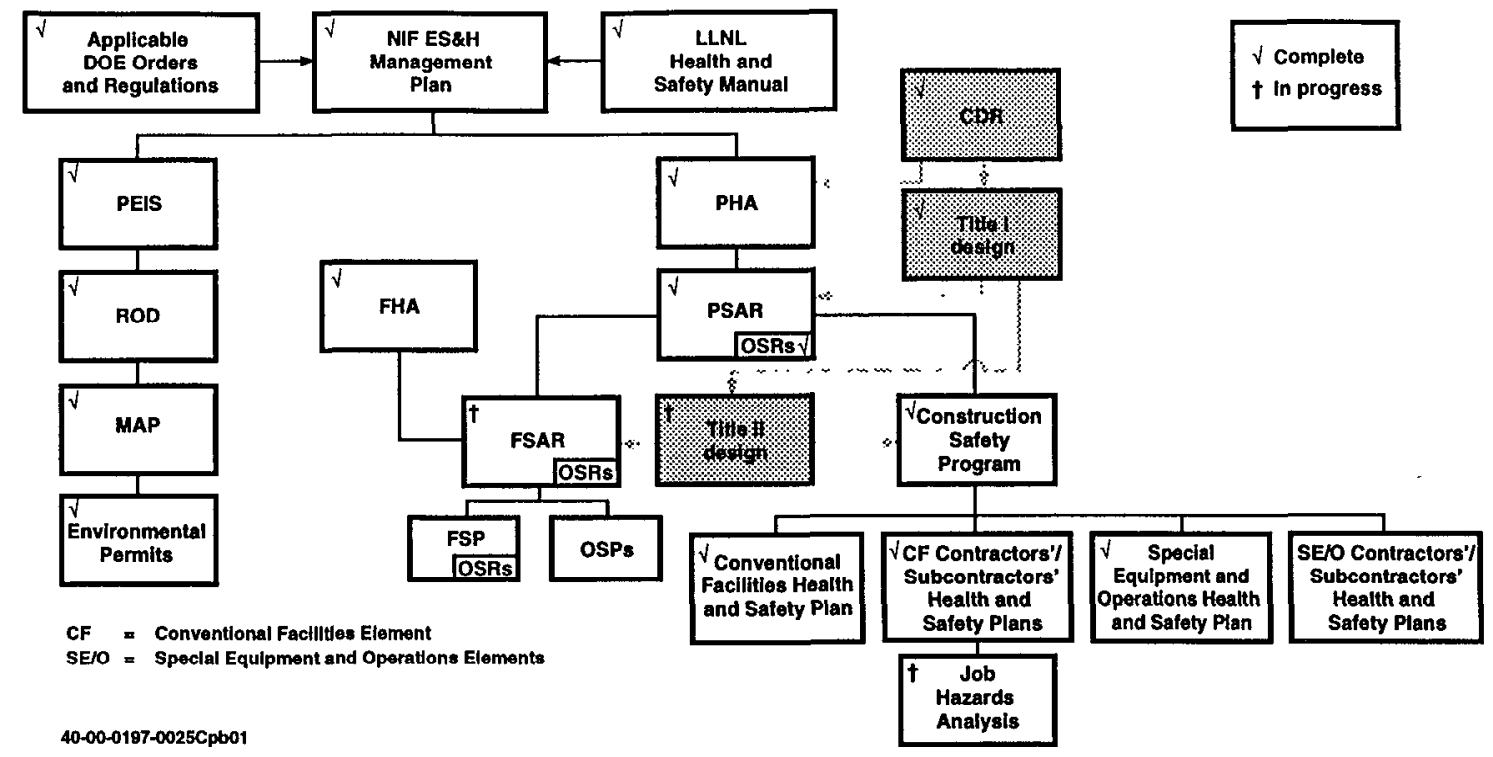

Figure 1. NIF ES\&H Documents

Safety Analysis Report that must be prepared in accordance with DOE Order 5481.1B. ${ }^{1}$ A Safety Analysis Report is documented, thorough review of facility hazards, accident analysis, and facility risk.

A PSAR was prepared for NIF and approved prior to the start of construction. The preparation included the following steps:

- hazard identification

- hazardous event development and evaluation

- assessment of relative risk

- quantitative evaluation of higher risk and/or consequence events.

Each of these steps is discussed in more detail below.

\section{A. Hazard Identification}

The hazard identification process began with a systematic review of planned NIF operations and existing design and safety documentation. Safety documentation prepared for other fusion facilities was also reviewed. This was supplemented by the use of hazard checklists. Additionally, project personnel were consulted, as were a team of Health and Safety professionals.

A hazard was considered to be anything having the potential to cause harm to workers, property, the public, or the environment. This included both energy sources and hazardous materials within the facility. External hazards and natural phenomena were also considered. The result

was a comprehensive list of hazards for the construction, start-up, and opcration phases.

\section{B. Hazard Evaluation}

Based on the identified hazards, potentially hazardous events that could result directly from the energy sources or hazardous materials, or from their interaction, were characterized. This involved consideration of the operational environment, operational activities, facility layout, component interfaces, and performing evaluations to understand interactions and how hazards could harm workers, the public, and the environment. Normal facility operation, and abnormal or accident conditions were considered. Preventive and mitigative features to control the hazards were identified through a review and understanding of the causes and potential impacts of the hazardous events. The resulting list of hazardous events was reviewed by Health and Safety professionals and project personnel.

The unique hazards at the facility (i.e. other than standard industrial hazards) primarily consist of laser light, high voltage/electrical hazards, tritium handling, use of chemicals, prompt radiation during shots, and neutron activation of air and structures in the target bay. In addition to hazards encountered during normal operations, nearly 50 accidents that could occur at the facility were identified. Each hazardous event was reviewed to identify potential causes, preventive or mitigative design features, and preventive or mitigative administrative features. These events are documented in the hazardous event table in the Preliminary Safety Analysis Report (PSAR). The PSAR 


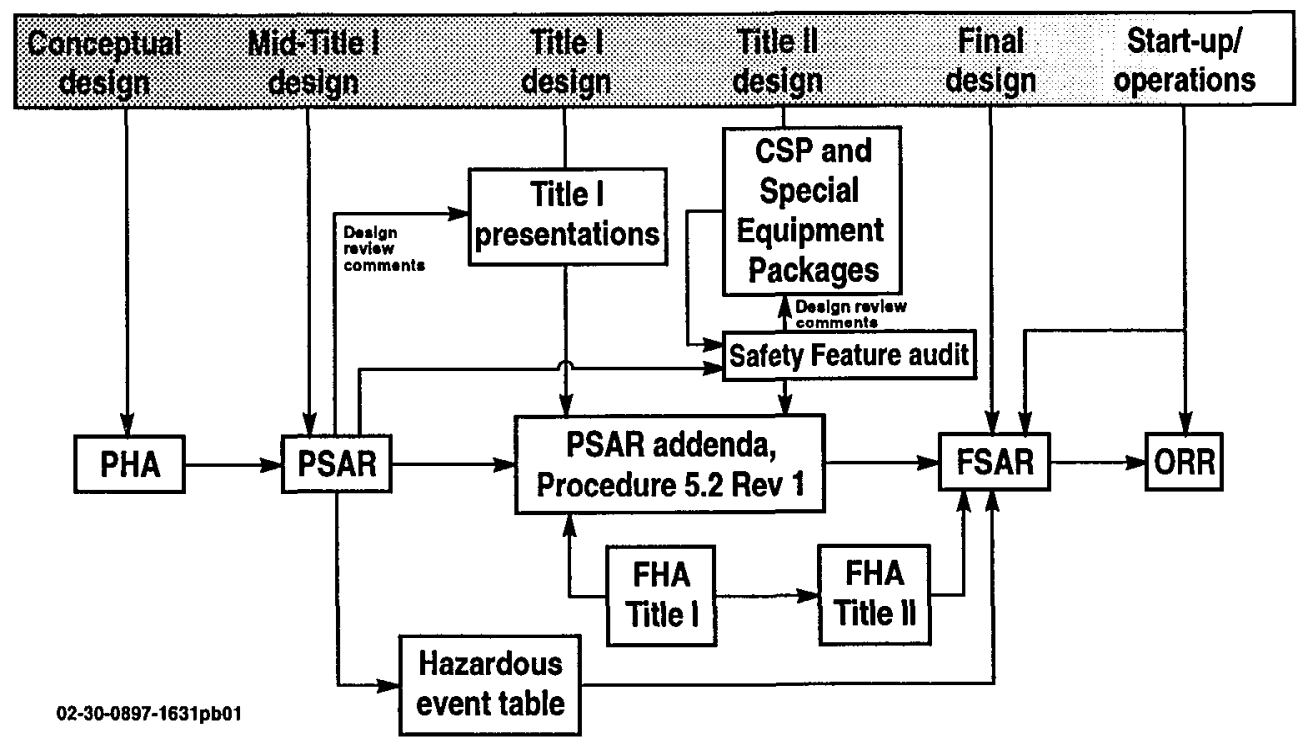

Figure 2. Evoluation of the NIF Safety Analysis

also describes, in general terms, the administrative programs that will provide the needed preventive and mitigative administrative controls identified in the hazardous events table.

\section{Selection of Events for Quantitative Analysis}

The analysis for NIF was carried out only to the level necessary to provide a convincing argument that the facility can be operated safely, with minimal risk to workers, the public, and the environment. This is consistent with the DOE concept of a "graded approach" to safety analysis. Thus, the PSAR analysis is largely qualitative, taking the form of a qualitative hazards analysis and a qualitative risk assessment, with only a few higher risk/higher consequence events analyzed quantitatively.

A relative risk assessment was performed to identify the higher risk and/or consequence events for quantitative analysis. In the relative risk assessment, each of the hazardous events identified for NIF was reviewed to gain a better understanding of event frequency and potential consequences, and how events compared to one another. A qualitative descriptor of event likelihood and consequences was assigned to each event. The event frequencies and consequences were combined using a risk matrix, so that each event ultimately had a risk label associated with it. The outcome was a relative risk ranking of all of the NIF events, and those presenting higher risk were identified for further study.

\section{Quantitative Evaluation of Higher Risk and/or Consequence Events}

The higher risk events identified were analyzed quantitatively in the PSAR. In addition, events that would result in the most severe consequences were also analyzed. This was done so that the bounding consequences from events at the facility would be known. Seven events were analyzed quantitatively in the NIF PSAR.

The analysis of events in the PSAR was bounding and conservative. The maximum facility inventory was assumed to be involved in the accident. No credit was taken for mitigating actions. Conservative weather conditions were assumed (stable atmosphere and low wind spced), so that dispersion in the atmosphere would be minimized and the resulting estimates of consequences downwind would be maximized.

From a radiological standpoint, the maximum exposed individual at the site boundary would receive a dose of $0.2 \mathrm{mrem} / \mathrm{yr}$ from routine operations at NIF. ${ }^{5}$ This includes a contribution from prompt radiation as well as some exposure from small releases of tritium and activated gases created in the target bay atmosphere. A bounding release accident, which considered a severe earthquake occurring at the time of a maximum yield shot, would result in a 75 mrem exposure at the site boundary. ${ }^{5}$

Routine releases of small amounts of volatile organics (e.g., solvents used for optics cleaning) may occur from NIF. These are expected to be well within local air quality limitations. A bounding release accident, involving an 
aircraft crashing into one of the capacitor bays and releasing mercury would result in a maximum offsite exposure less than the ERPG-2 level of impact.

\section{E. Safety Assurance Process}

1. Change Review Process. A change review process (CRP) was developed to evaluate design and operational changes, or changes in experimental parameters, that have occurred since mid-Title I, to determine if their impacts fall within the bounds of approved safety documentation. The CRP was derived from DOE Order $5480.21^{6}$ and consists of three levels of review or screening. For evaluations where it is determined that the change would excecd the bounds as documented in the PSAR, Laboratory Management approval is required. DOE will also be requested to concur, thereby accepting the increased risk associated with the change. The completed evaluation becomes an addendum to the PSAR.

We are currently in the middle of Title II design and some design changes have occurred since the PSAR was written. These have been reviewed with respect to the PSAR, and PSAR addenda have been prepared. All changes reviewed thus far have been found to be within the safety and environmental bounds defined in the PSAR. This process will continue through Title II design, until the final design is set, and the facility has heen constructed. PSAR addenda will be incorporated into the FSAR.

2. Title II Design Review Process and Safety Feature Audits. The goal of the Title II design review process is to produce equipment final designs that meet defined design criteria. The design criteria have been developed in a series of requirements documents, including the Preliminary Safety Analysis Report (PSAR).

The Conventional Facilities design, which includes the building and utilities, was performed by the Architect/Engineering firm Parsons Infrastructure and Technology Group. Parsons provided input to, and participated in, the preparation of the NIF PSAR. Having the design firm participate in preparing the safety documents ensured early "buy-in" on their behalf. Their participation also clearly established lines of communication and responsibility for the safety

\footnotetext{
b ERPG-2: Emergency Response Planning Guide, Level 2, as defined by the American Industrial Hygiene Association, is the maximum airborne concentration level of hazardous material below which it is believed that nearly all individuals could be exposed for up to one hour without experiencing or developing irreversible or other serious health effects or symptoms that could impair their ability to take protective action.
}

commitments contained in the safety documents. Subsequently, during Title II (detailed design), safety features of the NIF LTAB appeared in the construction subcontract packages (CSPs).

Checklists were developed from the PSAR, identifying design safety features for both special equipment (the laser, target chamber, etc.) and conventional facilities. A safety feature audit of the conventional facilities $100 \%$ Title II submittals was performed, using these checklists. The audits indicated that the great majority of required design safety features were incorporated in the submittals. Any discrepancies were resolved in the comment period for the $100 \%$ packages.

During the special equipment Title II design process, PSAR safety feature checklists are being included by designers in their review packages. These are usually only partially completed at early design review stages (e.g., $65 \%$ ). Upon completion of the $100 \%$ design review, drawings and procurement specifications will be audited in a manner similar to the Conventional Facilities. Because of the ongoing interaction during the design process, there is a high likelihood that all safety features will be incorporated into the design.

Further work is needed to ensure that the final as-built facility incorporates the design safety features so far documented. In addition, during Title III (construction and field engineering), we will be involved in the management of changes to the facility safety requirements and to the design. We plan to conduct safety audits of the as-built design documentation at the completion of work and to perform site audits of the completed facility (safety walk-downs) prior to beneficial occupancy by the Program. Special Equipment will be procured, inspected, and acceptance tested during Title III. Surveillances will be performed to ensure preventive and mitigative safety features identified during the design process are fabricated as designed and function properly. Subsequently, safety walk-downs and reviews of integrated experimental hardware and software systems will occur prior to, and in support of, the Operational Readiness Review (ORR) for the facility. The ORR will occur during 2001.

\section{F. Preparation of the FSAR}

The NIF PSAR was required prior to construction; it was approved by the institution in September 1996, and DOE-OAK concurrence was received in October 1996. The PSAR was based on mid-Title I design. The FSAR will be required before operations begin, and its preparation has just started. The FSAR will contain an expanded and possibly more detailed analysis compared to the PSAR 
and it will be based on the final design. The Fire Hazards Analysis (FHA) prepared during Title I will be updated in the near future. As needed, additional analyses of fires will be included in the FSAR. Approval of the FSAR will be required prior to operations in 2001 .

\section{G. Construction Safety}

A Construction Safety Program was developed for the NIF construction. ${ }^{7}$ The Program identifies core elements that must be included in the Health and Safety Plans prepared for NIF personnel and Construction Contractors/Subcontractors. The Health and Safety Plans must include safety responsibilitics of various organizations, management personnel and workers, safety protocols and procedures for specific work activities, how to manage accidents and emergency situations, pre-job planning (including preparation of job hazards analysis), and worker training requirements. The hierarchy of construction safety documents is illustrated in Figure 1.

Additional measures that have reduced the risk at the NIF construction site include:

- Zero injury techniques, e.g., individual responsibility for safety, pre-task planning, incentives, ...

- Monthly and quarterly safety audits

- Project safety team that addresses current safety issues at the site

- Construction safety officers and safety inspectors

- Changes based on Lessons learned.

The NIF construction safety program has been very successful to date, with only minor worker injuries occurring at the site.

\section{H. Operational Safety}

Operational safety implementation procedures will be derived from the NIF safety analysis. At LLNL, the Facility Safety Procedure (FSP) is the primary operational safety document. The FSP describes the safety and environmental controls for long-term activities at the facility, and must reflect the administrative controls identified in the FSAR. In particular, Operation Safety Requirements (OSRs), which are identified in the FSAR and which define the maximum safety boundaries for operations, must appear in the FSP, along with the controls to assure that operations stay within the OSRs.

Operational Safety Procedures (OSPs) may also be required during NIF operations, for limited term activities that are not adequately covered in the FSP. The OSP will address ES\&H issues and controls for the activity, and will either add to or limit the authorization provided in the FSP.

\section{THE ENVIRONMENTAL PROCESS}

The NIF environmental process is summarized in Figure 3. The process began with the publishing of a Notice of Intent to prepare an Environmental Impact Statement (EIS) in June, 1995. This was followed by public scoping meetings, the purpose of which was to solicit public comment on the scope of the PEIS, and to ensure that relevant public concerns would be addressed. NIF was included as a Project Specific Analysis (PSA) within the Programmatic Environmental Impact Statement (PEIS) for Stockpile Stewardship and Management (SSM). The resulting PSA is equivalent to a stand-alone EIS for the NIF. Details on the content and preparation process are provided below.

\section{A. Environmental Impact Statement}

The PSA explores a wide range of environmental impacts of NIF construction and operation at the alternative sites, as compared to their baseline of the no action alternative. ${ }^{8}$ It documents the upper boundary of the safety and environmental envelope. The document describes the Project and its purpose and need, considers site alternatives and Project design options, alternatives to the Project (including not'proceeding with the Project at all), delineates the affected environments, assesses environmental impacts (including impacts to cultural and paleontological resources, socioeconomics, and threatened, endangered or rare species), and suggests mitigation measures. The Draft PSA was prepared between the Conceptual design and Title I design activities. Public hearings on the draft document were held at the five candidate sites for NIF (LLNL, Los Alamos National Laboratory, Sandia National Laboratory, Nevada Test Site, and North Las Vegas), and in Washington D.C. Public comments were addressed and incorporated into the document, which was published as a final PEIS in September, 1996.

\section{B. Record of Decision}

After the final SSM PEIS was published, and other supporting documents prepared (covering cost and technical factors), the DOE made decisions on the various actions described in the document, and documented these in the Record of Decision. ${ }^{9}$ With respect to NIF, DOE decided to go forward with NIF construction, and to site NIF at LLNL. Issuance of the ROD allowed construction activities to begin. This included preparation of the MAP, and submission of requests for permits needed for construction (such as the Storm Water Pollution Prevention Plan). Before construction could begin, 


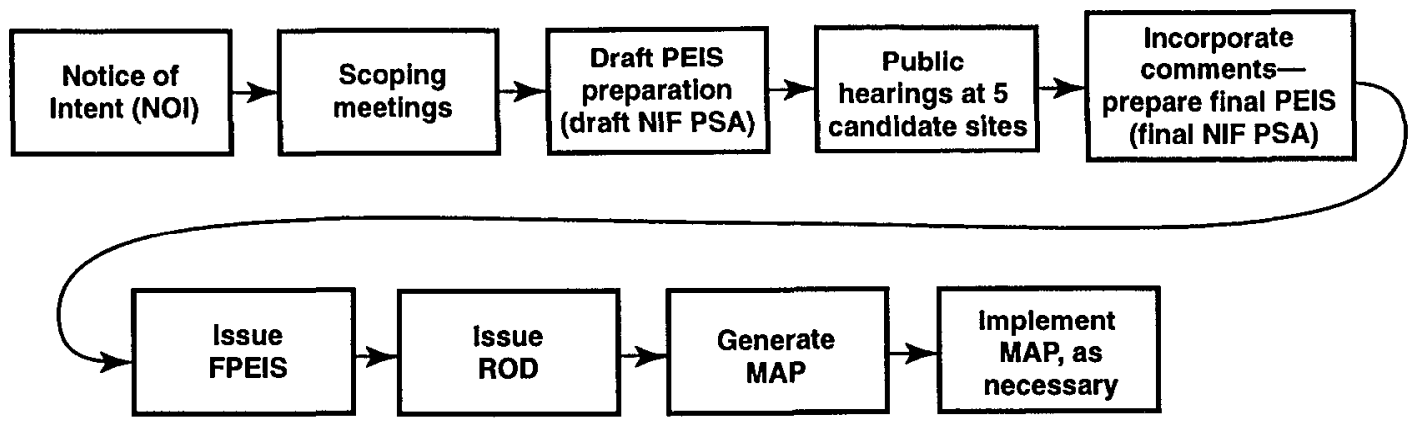

40-00-0598-1105pb01

Figure 3. The NIF Environmental Process

however, DOE went through a separate decision process to arrive at Critical Decision 3 (CD3), approval of construction start

\section{Mitigation Action Plan}

The Mitigation Action Plan ${ }^{10}$ expands upon the mitigation measurcs called out in the NIF PSA. It is a required part of the NEPA process. It further defines mitigation actions in terms of where they might be needed, how they will be conducted, and the time period in which they will be implemented. Responsibilities for administering the measures and monitoring them to determine the success of the mitigation measures are also identified.

Some mitigation measures identified in the NIF PSA and in the MAP have been implemented. For example, shortly after construction began, a pair of white-tailed kites nested in a tree a few hundred meters from the construction site. The white-tailed kite is a state-protected bird-of-prey. In the state of California, it is unlawful to collect, pursue, wound, kill, remove, disturb, or harm any nest or birds. A buffer zone around the nest was defined. As a result, NIFrelated trucks entering or leaving the construction site were required to take an alternate route to maintain noise at the nest at baseline levels. The buffer zone remained effective during the critical fledging months of juvenile kite development. Several kite pairs have returned to nest at LLNL this year, however, no nest have been built close enough to the main construction site to affect activities there.

\section{Other Environmental Activities}

During the excavation of the NIF site, two unexpected occurrences took place. First, during a grading operation, a construction worker found several buried capacitors, one of which was determined to be damaged and leaking.
Sampling determined that the capacitors contained diachlor (PCB). Construction was halted in the area, and Regulatory Agencies (DOE, EPA, etc.) and laboratory personncl evaluated the extent of the finding, and planned for the clean-up. Laboratory personnel continued to dig in the area, removing additional capacitors and any potentially contaminated soil. A total of 112 capacitors were found. These had apparently been buried at the site in the 1960s. Soil was removed from the site until sampling indicated no further contamination. The contaminated soil and capacitors were disposed of at a hazardous waste facility.

Another occurrence was the discovery of fossil animal bones during the excavation. The most noteworthy of these was the uncovering of bones of the Mammuthus columbi, or Mammoth. These bones were discovered by workers digging a utility trench. Upon discovery of the bones, construction was halted in the area, and the LLNL archeologist and Curator of the UC Museum of Paleontology visited the site. The Department of the Interior (DOI) has jurisdiction over antiquities found on lands owned by the U.S. Government, and grants permits for excavation of antiquities. DOE applied for and received a permit from the DOI National Parks Service to excavate the bones. LLNL hired a paleontologist recommended by the UC Museum of Paleontology to direct the excavation and preserve the bones. The finding included teeth, jaw bone, skull, tusk, and several vertebrae and ribs. Figure 4 shows several photos taken during the removal of the bones. The excavation and careful removal of the bones was accomplished within one week. They have been transferred to UC and are currently being stored awaiting preservation at the UC Museum of Paleontology. The Smithsonian Institution has first right to the excavated materials. However, they declined the option to add the bones to their collections. Instead, the bones will be placed under the curatorship of the UC Museum of Paleontology. 


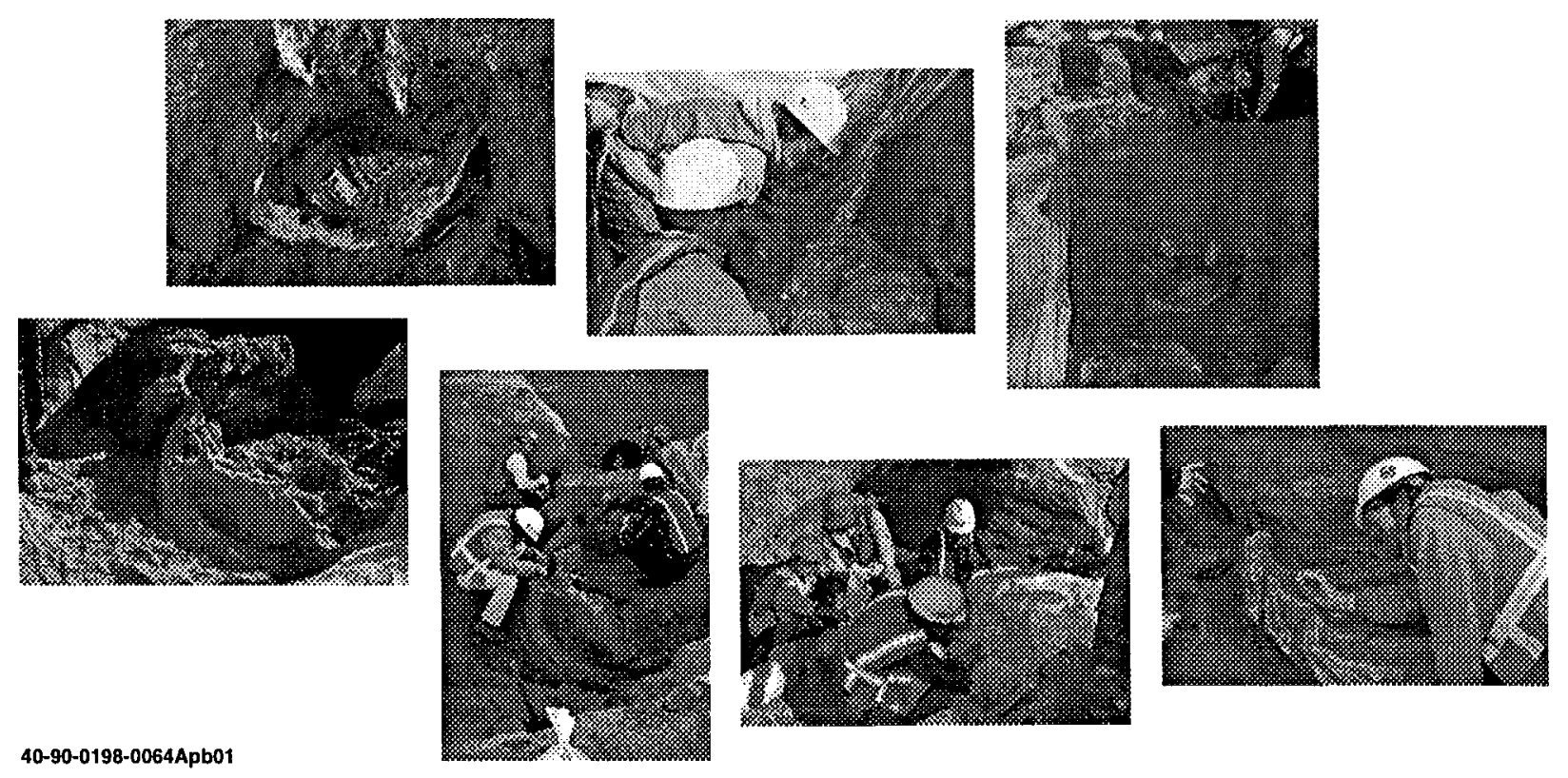

Figure 4. Excavation of Mammoth Bones at the NIF Construction Site

\section{SUMMARY}

Safety and environmental issues associated with NIF have been addressed in various safety and environmental documents. A NIF PSA was included in the SSM PEIS, published in September 1996. Follow on activities from that include implementing various actions that will mitigate the environmental impacts of constructing and operating NIF. The NIF safety basis is currently documented in a PSAR. The FSAR is in preparation and will be completed and approved prior to operations in 2001. These documents, and the ongoing interaction with Project (design and construction) and ICF/NIF Program (operations) personnel assure that NIF will be built and operated with minimal impact to workers, the public, and the environment.

\section{REFERENCES}

1. Department of Energy, DOE Order 5481.1B, Safety Analysis and Review System, 1986.

2. National Environmental Policy Act, 1969.

3. DOE Order 451.1, National Environmental Policy Act Compliance Program, U.S. Department of Energy, 1997.
4. Brereton, Preliminary Hazards Analysis for the National Ignition Facility, Lawrence Livermore National Laboratory, UCRL-ID-116983, Oct. 1993.

5. Lawrence Livermore National Laboratory, National Ignition Facility Preliminary Safety Analysis Report, UCRL-ID-123759, Sept. 1996.

6. DOE Order 5480.21, Unreviewed Safety Questions U.S. Department of Energy, 1991.

7. Lawrence Livermore National Laboratory, NIF Construction Safety Program, UCRL-ID-125990, current Rev.

8. National Ignition Facility Project Specific Analysis, Appendix I of the Programmatic Environmental Impact Statement for Stockpile Stewardship and Management, U.S. Department of Energy, DOE/EIS0236, Sept. 1996.

9. Memorandum for the Secretary, from V.H. Reis, through C.B. Curtis, Stockpile Stewardship and Management Program Environmental Impact Statement Record of Decision, U.S. Department of Energy, Dec. 19, 1996.

10. Department of Energy, Office of Defense Programs, Oakland Operations Office, Mitigation Action Plan, National Ignition Facility, Jan. 1997. 


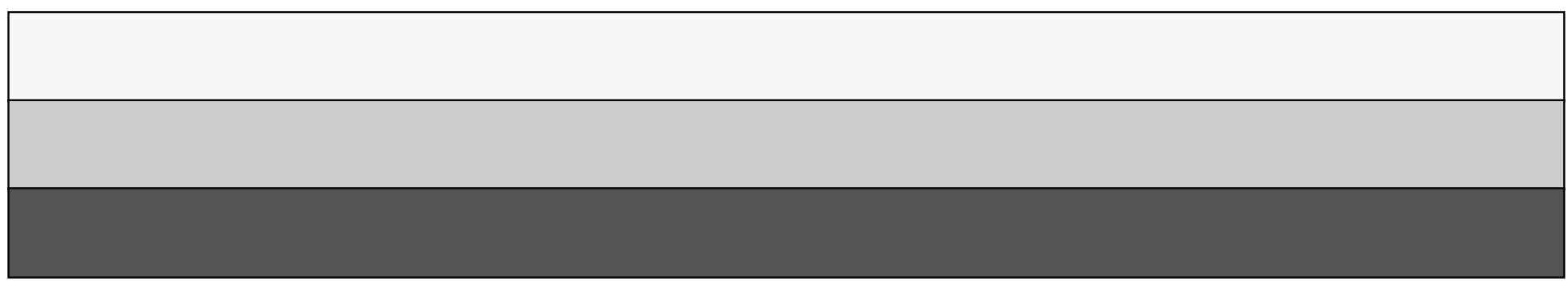

